Utah State University

DigitalCommons@USU

1970

\title{
Commercial Production and Management of Wild Bees--a New Entomological Industry
}

George E. Bohart

Utah State University

Follow this and additional works at: https://digitalcommons.usu.edu/piru_pubs

Part of the Entomology Commons

\section{Recommended Citation}

Bohart, G. E. 1970. Commercial Production and Management of Wild Bees--a New Entomological Industry. Bull. Entomol. Soc. Amer. 16(1): 8-9. March 1970.

This Article is brought to you for free and open access by the Pollinating Insects Research Unit at DigitalCommons@USU. It has been accepted for inclusion in All PIRU Publications by an authorized administrator of DigitalCommons@USU. For more information, please contact digitalcommons@usu.edu.

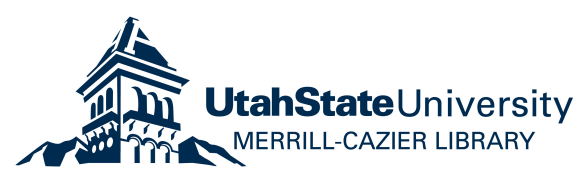




\title{
Commercial Production and Management of Wild Bees-
}

\section{A New Entomological Industry ${ }^{1}$}

\author{
By G. E. Bohart \\ Entomology Research Division, Agricultural Research Service, Logan, Utah 84321
}

\begin{abstract}
As early as 1940 , agronomist H. M. Tysdal emphasized the importance of wild bees for alfalfa seed production. He noted the particular value of native species of leafcutting bees in the Great Plains and alkali bees, Nomia melanderi Cockerell, in the Intermountain West, and recommended research on these and other wild bees. Apiculturists G. H. Vansell and F. E. Todd in 1945 demonstrated the value of honey bees for alfalfa pollination in central Utah and at the same time mentioned the effectiveness of alkali bees as alfalfa pollinators where they were abundant. By 1950 California seed growers were renting honey bees for alfalfa pollination and obtaining thereby some outstanding seed yields (up to 1400 pounds per acre). Unfortunately, honey bees collected very little pollen from alfalfa in areas north of southern California and, as a result, their usefulness was somewhat limited. In the early 1950 's, after alkali bees were touted as pollinators by the pollination laboratory at Logan, Utah, by W. P. Stephen at Corvallis, Oreg. and by H. F. Menke at Wapato, Wash., farmers of Oregon, Washington, Idaho, and Wyoming (in areas where alkali bees were abundant) began growing alfalfa seed more extensively and intensively than previously. At first, management of the pollinators was limited to exercising some care in the use of insecticides, a few efforts to fence of known nesting areas, and attempts to increase the size of the sites by expanding the zones of seepage in which the bees were nesting.
\end{abstract}

By the mid-1950's, W. P. Stephen had worked with growers in Oregon and Idaho to develop "artificial" nesting sites by making excavations, lining them with plastic to prevent water loss, and providing a gravel layer to store and distribute water. Many of these sites were populated by bees flying in from "natural" sites, and others were stocked with cores of soil moved in the spring from existing sites. During this period, studies on the living requirements and various management aspects of alkali bees were intensified, not only at Logan and Corvallis, but also at Prosser, Wash., by K. E. Frick and E. C. Klostermeyer and at Parma, Idaho, by N. D. Waters. Soon efforts were being made to establish alkali bees in areas where they were not known to exist (at least in appreciable numbers), as, for example, in the Central Valley of California, South Dakota, and in British Columbia and Alberta. Many of these efforts failed, but some success was achieved in the northern San Joaquin Valley of California and in the Okanagan Valley of British Columbia.

By the late 1950's, hundreds of "artificial" nesting sites had been prepared (primarily in the Columbia River Basin near Walla Walla, Wash., and in the Treasure Valley region of Idaho and Oregon). Success with these sites was variable, and populations in the "natural" sites tended to fluctuate in unpredictable fashion. Nevertheless, populations of alkali bees showed a general upward trend, and the number of acres being farmed for alfalfa seed, as well as yields per acre, increased. The best fields began yielding from 1,500 to 2,000 pounds per acre as compared with a national average of about 150 pounds. The Northwest for the first time became a leading area in tonnage of alfalfa seed as well as in yields per

\footnotetext{
${ }^{1}$ In cooperation with Utah Agricultural Experiment Station.
}

acre, with the use of alkali bees well recognized as the dominant reason.

It became apparent that, to some degree, a new entomological industry had appeared-one of purposefully managing a "wild" bee to support crop production. The money involved was not particularly impressive, unless measured against the amounts involved in a few other entomological industries such as the culture of cochineal scales for dye stuffs, lac scales for lacquers, and wax moth larvae for fish bait. The average "artificial" nesting site of about 3,000 square feet probably cost about $\$ 0.20$ per square foot to build and stock. If 200 such sites were built, the total cost would be about $\$ 120,000$. This is a minor investment relative to the magnitude of the beekeeping industry, but it was the prime mover in the striking development of the alfalfa seed industry in the Northwest.

Another commercial aspect of the use of alkali bees was the sale of soil cores from established sites. The going price ranged from $\$ 0.50$ to $\$ 1.00$ per square foot, and some farmers sold several thousands of dollars worth each year. The buyer had to replace the soil, and this usually improved the site. Natural increase among the bees allowed the farmer to "have his cake and eat it, too."

It was obvious by the early 1960 's that managing alkali bee beds was not all coasting. Many older sites had lost so much population as to be almost worthless. New or aggravated pest problems resulted in insecticide applications that decimated populations on the fields. Drainage often resulted in the drying up of formerly attractive areas for nesting. For example, in the Riverton area of Wyoming, the alfalfa seed industry died out altogether as a result of a combination of area-wide drainage efforts and some alkali bee disease problems apparently peculiar to the area.

Fortunately, by this time the alfalfa leafcutting bee, Megachile rotundata, had spread through the area, and research on its biology and management had proceeded to the point where farmers could begin utilizing it.

Megachile rotundata probably reached this country from southeastern Europe or southwestern Asia in the mid1930 's. It was collected in several places east of the Mississippi River in the 1940's and was more or less simultaneously collected in Utah, California, and Oregon in 1955. However, it was not recognized as a new element in the Intermountain fauna until 1958, when its rapid increase caused some second thoughts, and specimens were sent to $T$. B. Mitchell at Raleigh, N. C., for study.

Research was immediately launched in Utah, Idaho, Oregon, and Washington. A few farmers had observed the bees nesting in nail holes even before 1958 and had begun drilling holes in their outbuildings to encourage them to nest. By 1960 a few farmers in all of the Northwestern States, including Utah and Nevada, were placing boards drilled with holes and containers of soda straws on and in their outbuildings to encourage the bees to nest. Interest by growers developed rapidly, especially in areas where alkali bee populations had declined or had always been marginal.

In the early 1960's the bees were sent to researchers and farmers alike in California, Alberta, the Great Plains States, and even some prairie areas. Requests for bees came from 
Chile, where they became successfully established, and from eastern European countries. Seed yield increases in Alberta were especially dramatic, since yields there had been consistently low because of inadequate pollination. G. A. Hobbs of the Dominion Experiment Station at Lethbridge played a large part in the Alberta developments.

Use of alfalfa leafcutting bees expanded tremendously in nearly all of the Western States of the United States and in Canada in the late 1960's. Management techniques have not changed basically, but improvements have been made each year. Some of these have been brought about by investigators, but in many cases growers themselves and people from various industries have made valuable innovations and refinements. The greatly increased interest in leafcutting bees was accompanied by a further increase in seed production and yields per acre. Although it was found that the bees could be successfully managed in most parts of the country, seed production did not spread correspondingly. Areas where seed production had always been marginal for climatic reasons could realize increased production, but they still could not compete successfully with the better efficiency of areas with more sunshine for seed ripening and harvesting.

An interesting recent development has been the adoption of leafcutting bees in California, where honey bees, Apis mellifera L., have been successfully used for many years. Relatively high yields have been realized in California since the early 1950's through a combination of renting honey bees for pollination, a long growing season, many waterings to bring additional bloom, careful farming, and excellent harvesting conditions. However, irrigation water was getting more expensive, insecticide problems were becoming more difficult to manage on a long-season basis, and honey bees were not collecting alfalfa pollen early in the season when the other problems were minimized. In the rice-growing area of the Sacramento Valley, introduction of leafcutting bees on a large scale allowed two separate crops of alfalfa seed to be grown in the same year, thanks to good pollination of bloom in May and early June.

The alfalfa leafcutting bee industry has developed several segments. Farmers soon learned that drilling boards was a losing operation. They couldn't get enough holes drilled, and the holes did not hold up because of poor quality drills and lumber for the purpose. Consequently, manufacturers of "bee boards" sprang up. Farmers couldn't expand their populations rapidly enough, especially as they were getting started, so they began buying bees from growers with large populations already developed. These were bought as "filled boards" or "filled straws" or simply by-the-bee in loose cocoons. Farmers were placing trap-nests in favorable locations wherever alfalfa (not necessarily for seed) was grown. Housewives, small boys, and other entrepeneurs were soon asking for and getting rentals for such locations. Some farmers and a few beekeepers finally began providing a leafcutting bee pollination service for their neighbors. Sometimes this enabled them to expand populations for their own use and extract a good fee at the same time. N. D. Waters has said that in the area around Parma, Idaho, where the various segments of the industry are rather well developed, there is more money spent and earned in the leafcutting bee industry itself than in the sale of alfalfa seed.

Cost and benefit factors associated with the use of alfalfa leafcutting bees are the subject of a two-year USDA cooperative agreement grant to the Agricultural Economics Department of Utah State University. It will be interesting to see the conclusions about this industry and from the survey to make some predictions concerning the future.

Meanwhile, alkali bees have not been entirely forgotten. After several bad years in the mid-1960's, populations have been on the upswing in most areas. The Columbia River people never despaired of them, and interest is returning in Treasure Valley. At the moment, intensive research is underway in Utah (under L. R. Batra) and in Washington (under C. A. Johansen) on fungus disease problems in the nesting sites. Our recommendations to the seed growers have always been to use both species of "wild" pollinators, and honey bees, too, wherever feasible.

\section{REFERENCES CITED}

Tysdal, H. M. 1940. Is tripping necessary for seed setting in alfalfa? J. Amer. Soc. Agron. 32:570-85.

Vansell, G. H., and F. E. Todd. 1945. Alfalfa tripping by insects. Ibid. 38:470-88.

\author{
Reprinted from the \\ Bulletin of the Entomological Society of America \\ Volume 16, Number 1, pp. 8-9, March 1970
}

